\title{
From One Stress Test to Another: Lessons for Healthcare Reform from the Financial Sector
}

\author{
Shirley KEMPENEER*
}

\begin{abstract}
The financial crisis in 2008 and the COVID-19 pandemic today have made it clear that both financial and medical crises spread pervasively across borders. The financial crisis proved that the health of the entire European banking system stands and falls with the health of a single systemically important bank. As such, in the past decade, European Union (EU)-wide cooperation and regulation have been strengthened to ensure financial health across Europe. Today, the COVID-19 crisis reveals the de facto existence of a European healthcare system, where Member States' medical health is interlinked and challenged. It too highlights the need for a more coordinated approach. This paper will draw lessons from European financial regulation and stress testing to make recommendations for EU-wide healthcare. The paper will show the latent benefits that a stress test might have on healthcare performance through mechanisms of governmentality. Moreover, it will pinpoint shortcomings in the financial stress test that could pose looming dangers for a European Health Union, such as a lack of de facto risk sharing. The paper concludes with pragmatic suggestions for a way forward in European healthcare regulation.
\end{abstract}

\section{INTRODUCTION}

In his 2018 State of the Union Address, President Juncker quoted French philosopher Pascal Blaise:

I like things that go together. In order to stand on its own two feet, Europe must move forward as one. To love Europe, is to love its nations. To love your nation is to love Europe.

Despite the diversity in national contexts, Member States are intricately connected in many ways, calling for an overarching European regulatory system and a strong European Union (EU). This became especially clear during the financial crisis, when the interconnectedness of the banking system caused risk to spill over national borders and contaminate the entire European sphere. It is clear again now, as the COVID-19 pandemic reveals how Member States' medical health is interlinked and challenged. The complexity of transnational policy

\footnotetext{
Assistant Professor, Department of Public Law and Governance, Tilburg University, Tilburg, The Netherlands; email: s.kempeneer@tilburguniversity.edu. Many thanks to the anonymous reviewer at the European Journal of Risk Regulation, as well as Lydie Cabane and Martijn Groenleer, who all provided helpful comments. 
issues simultaneously enhances both the need for a more coordinated approach and the difficulty of creating this across varying contexts. Moreover, it has become tragically clear that Member States' financial and healthcare systems can easily be overwhelmed, calling for more European guidance and unity.

Not all healthcare systems were equally challenged by COVID-19. The Italian system, for instance, regarded as one of the top ten in the world, ${ }^{1}$ was still hit hard. Despite a robust hospital network in Lombardy, the limited home and long-term care available to the elderly might have hampered recognition of COVID-19 in its earlier stages. ${ }^{2}$ Moreover, budget cuts across Europe, but most notably in Italy and Spain, had a profound impact on healthcare, such as layoffs of essential personnel, hiring and salary freezes, shorter hospital stays and fewer hospital beds. ${ }^{3}$ This meant that healthcare systems operating in a context of austerity were particularly overwhelmed and not suited or prepared to respond to the pandemic.

Political calls have surfaced for the urgent creation of a European Health Union, as well as EU-wide healthcare stress tests. ${ }^{4}$ Although the notion of conducting stress tests of healthcare systems received support from many angles, few authors discuss what this could look like in practice. Meanwhile, in the financial sector, stress tests have been conducted for the past decade following EU Regulation 1093/2010. ${ }^{5}$ As such, it seems advisable to look in their direction for lessons to be learned. ${ }^{6}$ For the purpose of this paper, I provide three particular lessons for a stress test of the healthcare system. What becomes clear is that standardisation across Member States is not the answer; solidarity is. Neither a Banking Union nor a Health Union can exist on common standards and information sharing alone - respect for local contexts and the willingness to share risk is necessary.

\section{LESSON 1: STANDARDISATION IS NOT ALWAYS THE SOLUTION}

Stress tests measure and compare the resilience of various systems. The EU-wide banking stress test aims to make a standardised comparison of banks' risk across Europe. Similarly, the objective of a healthcare stress test seems to be to evaluate Member States' ability to handle pandemics and other healthcare crises. This assumes that

1 L Monasta et al, "Italy's Health Performance, 1990-2017: Findings from the Global Burden of Disease Study 2017" (2019) 4 Lancet Public Health e645.

2 S Volpato, F Landi and RA Incalzi, "A Frail Health Care System for an Old Population: Lesson Form the COVID-19 Outbreak in Italy" (2020) 75 Journals of Gerontology. Series A, Biological Sciences and Medical Sciences 126.

3 See M Carney and B Ostrach's contribution at <http://somatosphere.net/2020/austerity.html/>.

4 Group of the Progressive Alliance of Socialists and Democrats in the European Parliament, "Letter for a European Health Union", 7 May $2020<$ https://www.socialistsanddemocrats.eu/sites/default/files/2020-05/european-healthunion-letter-200507.pdf>.

5 This Regulation mandated the European Banking Authority (EBA) to initiate and coordinate EU-wide stress tests to assess the resilience of financial institutions to adverse market developments. These are complemented by the European Central Bank (ECB) stress tests (also including smaller banks) under the Single Supervisory Mechanism (SSM); see EU Regulation 1024/2013. The test is part of SSM banks' Supervisory Review and Evaluation Process (SREP). The SREP shows where a bank stands in terms of capital requirements and risk mitigation and sets key objectives for banks to address identified issues. One aspect can be an additional Pillar 2 Capital Requirement (P2R) and Pillar 2 Guidance (P2G; which is not legally binding).

6 See also the contribution by A-L Beaussier and L Cabane in this issue for lessons from the financial sector on crisis management. 
healthcare systems across Europe, or banks, are comparable. However, comparing banks or healthcare systems in different Member States is not self-evident, as these systems differ significantly within and among countries. Banks have different business structures, asset profiles and risk appetites. Healthcare systems across Member States also have fundamental differences: they are composed of diverging health facilities, specific organisations, departments, insurance services and community care systems. ${ }^{7}$ The literature on commensuration teaches us that many of the things we try to compare are not comparable, but need to be made comparable. Commensurating healthcare systems means taking diverse qualitative national and regional systems and trying to find a way to homogenise them on a common metric, to enable comparison. ${ }^{8}$

Research on the banking stress test shows that commensuration and standardisation require a lot of work and should not be seen as a panacea. In allowing some room to negotiate their "incommensurability", banks were able to engage in meaningful dialogue with supervisors, explaining the importance of their unique characteristics and improving the overall understanding of financial health and risk. ${ }^{9}$ For example, rather than enforcing one standardised way of calculating the risk of their assets in a crisis situation, banks were allowed to submit their own context-specific calculations. They submitted narratives explaining these calculations that were then discussed with and vetted by supervisory teams. Banks were challenged sufficiently so as to avoid excessive gaming, and meanwhile a dialogue was created that improved the overall understanding of risk in various contexts. To be sure, some common standards were left in place to ensure a sufficiently level playing field in the exercise.

These kinds of bottom-up indicators, developed in a participative way, are called "active indicators". ${ }^{10}$ This type of indicator suggests an iterative approach, where dialogue is crucial - and not only technical dialogue regarding data availability and statistical methods, although this is important too, but also substantive and normative dialogue regarding prioritisation and conceptualisation. The work of Annabel Jackson $^{11}$ shows that top-down indicators disempower organisations by preventing them from pursuing their own priorities and forcing them to direct energy into displacement activities. Moreover, top-down indicators impose administrative requirements on organisations in addition to their own, more finely tuned systems of performance measurement and evaluation, which will likely differ across systems. Bottom-up indicators recognise the value that contextualised, rather than standardised, performance measurement systems can have. It seems key to build on the systems already in place in Member States, rather than adding yet another (administrative) layer of requirements.

\footnotetext{
7 KL Ebi et al, "Stress Testing the Capacity of Health Systems to Manage Climate Change-Related Shocks and Stresses" (2018) 15 International Journal of Environmental Research and Public Health 2370.

8 WN Espeland and ML Stevens, "Commensuration as a Social Process" (1998) 24 Annual Review of Sociology 313.

9 S Kempeneer and W Van Dooren, "The Incommensurables: The Arduous Art of Making a Regulatory Indicator" (2020) 14 Critical Policy Studies 285.

10 C Stone, "Problems of Power in the Design of Indicators of Safety and Justice in the Global South" in KE Davis et al (eds), Governance by Indicators: Global Power through Quantification and Ranking (Oxford, Oxford University Press 2012).

11 A Jackson, "Falling from a Great Height: Principles of Good Practice in Performance Measurement and the Perils of Top down Determination of Performance Indicators" (2005) 31 Local Government Studies 21.
} 
As such, a first lesson for an EU-wide healthcare stress test is to recognise the value of a contextualised, rather than a standardised exercise. As such, contextualised information on resilience and risk of national systems is vital. A stress test that aims to compare national healthcare systems will likely bring up the debate on EU-wide (minimum) healthcare standards and deepening integration. ${ }^{12}$ Although some common guidelines may be helpful, it is important to be mindful to tailor standards to the needs of Member States. It is unlikely that there is a one best system of healthcare for all Member States in the EU. Moreover, different healthcare systems operate on different budgets, and as such might not necessarily have the means to reach these targets. Therefore, a discussion on EU-wide healthcare standards should be accompanied by a discussion on a common fiscal policy.

Rather than setting EU-wide standards, it might be more beneficial to create an environment for learning where Member States can engage in meaningful dialogue and exchange best practices, under the coordination and supervision of an EU agency. This would lead to a more meaningful integration of practices that stems from joint learning, rather than imposed harmonisation of targets that might only exist or seem useful on paper, and most likely be subject to gaming. For instance, although demanding a fixed number of intensive care unit (ICU) beds per capita may seem to be a simple and common-sense response, it is not necessarily sustainable, as (context-dependent) factors that affect strain on ICU beds seem more important for resilience than the number of ICU beds available. ${ }^{13}$

\section{LESSON 2: A STRESS TEST IS MORE THAN A PASS/FAIL EXERCISE}

Building on this first lesson, a second lesson from the stress test would be to remove the focus on the results of the stress test. The results of performance indicators, such as a stress test, are usually seen as key information for regulating behaviour and improving performance outcomes. Those who score well are rewarded, and those who do not are asked to amend their behaviour. Although many success stories exist regarding how performance measurement positively affects performance outcomes, in recent years, performance indicators have had to endure severe criticism. They are said to encourage tunnel vision, create perverse incentives, exist solely as symbolic communication exercises and ultimately fail to improve performance. ${ }^{14}$ Even sympathetic analysts ${ }^{15}$ acknowledge the adverse effect of performance indicators. This raises the question of how a stress test of healthcare systems can actually contribute to better performance outcomes. Research on the EU-wide banking stress test suggests that, rather than learning from results, organisations can learn from

\footnotetext{
12 Also discussed by M Guy and N Coghlan in this issue.

13 OG Rewa et al, "Indicators of Intensive Care Unit Capacity Strain: A Systematic Review” (2018) 22 Critical Care 86.

14 C Boswell, "The Double Life of Targets in Public Policy: Disciplining and Signalling in UK Asylum Policy" (2015) 93 Public Administration 490.

15 P Dunleavy et al, "New Public Management Is Dead - Long Live Digital-Era Governance" (2005) 16 Journal of Public Administration Research and Theory 467.
} 
producing information. As such, indicators can be latently constitutive of the performances they intend to measure.

In the EU-wide banking stress test, banks configured new habits and patterns of behaviour because the stress test required them to produce large amounts of data under heavy time pressures, encouraging processes of self-regulation. ${ }^{16}$ For instance, banks updated information technology systems, increased communication across departments and improved internal processes so as to be able to assess better and in more detail how a crisis would affect them. Although they engaged in internal analyses of resilience prior to the stress test, these exercises were never as encompassing and detailed. Having to calculate a stress test not only for internal or even national purposes, but instead in an EU-wide exercise that was heavily scrutinised, encouraged banks to invest in their risk-assessment abilities. As such, the stress test latently caused important long-term changes in attitudes, habits and beliefs.

This can be tied to Foucault's notion of governmentality. ${ }^{17}$ Rather than directly regulating behaviour, the EU-wide banking stress test steered how banks selfregulate, ultimately improving performance outcomes. In the case of the banking stress test, extensive data requirements were key to initiating change. Research on the effect of performance intelligence on healthcare performance ${ }^{18}$ supports the idea that this might be the case for the healthcare sector, too. For instance, a stress test that requires healthcare systems to collect better and more timely data can also help in guiding their day-to-day decisions, as well as decisions in crisis. To be sure, in a context of austerity and health budget cuts across Europe, healthcare systems would most likely need financial support in order to collect, clean and analyse these data. Discussions on developing an EU-wide healthcare stress test also necessitate discussions on a common fiscal policy in Europe, which I address further in the third lesson below.

Steering through governmentality, rather than results, can help to avoid decoupling: organisations claiming to fulfil requirements while internally not changing anything. ${ }^{19}$ In steering by results, organisations may try to circumvent actual change by window dressing or gaming results rather than actually practicing organisational reform. The healthcare sector is known to be especially creative in these strategies, with examples including removing wheels from trolleys to make them count as beds and admitting inpatients via the emergency department to boost the proportion of patients seen in under four hours. ${ }^{20}$ In steering through governmentality, healthcare systems might be obliged to collect better and more timely data in a stress test, rather than simply reach

\footnotetext{
16 S Kempeneer and W Van Dooren, "Using Numbers That Do Not Count: How the Latent Functions of Performance Indicators Explain Their Success" (2019) International Review of Administrative Sciences doi: 10.1177/ 0020852319857804.

17 M Foucault, The Government of Self and Others: Lectures at the College de France, 1982-1983 (London, Palgrave Macmillan 2011).

18 D Kringos et al, "Managing COVID-19 within and across Health Systems: Why We Need Performance Intelligence to Coordinate a Global Response" (2020) 18 Health Research Policy and Systems 1.

19 JW Meyer and B Rowan, "Institutionalized Organizations: Formal Structure as Myth and Ceremony" (1977) 83 American Journal of Sociology 340.

20 S Bowen and S Kreindler, "Indicator Madness: A Cautionary Reflection on the Use of Indicators in Healthcare" (2008) 3 Healthcare Policy 41.
} 
certain (gameable) targets. It is likely that once collected for a stress test, these data could be used for other organisational purposes that improve day-to-day performance.

As such, a second lesson is not to simply design the stress test as a pass/fail exercise, requiring healthcare systems with poor results to reform. Such an exercise is very likely to encourage gaming, lead to overly optimistic results and result in organisational decoupling rather than actual change in the quality of healthcare systems. Instead, careful work is necessary to design an exercise that actually encourages Member States to rethink and reform their healthcare systems where necessary. Designing a stress test for the healthcare sector that steers behaviour through mechanisms of governmentality, rather than solely through management by results, holds many benefits and seems a promising avenue to explore. It is imperative that healthcare systems do not simply see a stress test as a compliance exercise that stands apart from their day-to-day functioning. A stress test should be designed that (latently) ties into and feeds into how healthcare organisations self-assess their resilience. This is an important strategy to avoid decoupling and to guarantee actual organisation change, and consequently to foster an actual improved resilience of the European healthcare sector at large. ${ }^{21}$

\section{LESSON 3: PLAN FOR FAILURE}

Although the second lesson teaches us not to be overly focused on the results, they cannot be completely ignored. A third lesson from the banking stress test is to plan for failure. What happens with healthcare systems that might "fail" the stress test? In recent years, it has become clear that crises, such as the financial crisis and the current COVID-19 pandemic, are increasingly systemic. Such transboundary crises call for transboundary crisis management capacities. ${ }^{22}$ If one link in the system is weak, the whole system risks collapse. This was clear in the financial crisis, and it became clear once more during the current COVID-19 pandemic. When national healthcare systems do not have the capacity to contain a crisis, this poses a risk for the entire system. As such, it is in the common interest to engage in risk sharing and to increase transboundary solidarity.

Unfortunately, this was lacking in the EU-wide banking stress test. Despite the systemic nature of financial crises, it remains predominantly a national responsibility to deal with failing or fragile banks. ${ }^{23}$ To be sure, on paper, a single resolution mechanism (SRM) was proposed shortly after the crisis to ensure an orderly (and European) resolution of failing banks. In practice, developing resolution planning was piecemeal, and it is only since 2019 that banks have been covered by a

\footnotetext{
21 To be sure, such an exercise would be costly (as was the banking stress test), and as such an impossible investment for certain healthcare systems operating under budget constraints. This again points towards a need for a common fiscal policy.

22 F Attinà, A Boin and M Ekengren, "Designing EU Crisis Management Capacities: Filling the Glass" (2014) 22 Journal of Contingencies and Crisis Management 129.

23 This had many consequences. Without a European backstop to guarantee systemic health, failing banks posed a serious risk of distrust in financial markets. As such, the stress test was made less severe and the initial pass/fail hurdle for banks was removed, which weakened the entire exercise.
} 
resolution plan. Moreover, the SRM approach requires that recapitalisation should take place first using private capital, then national public capital, and only as a last resort the Single Resolution Fund (SRF). For good measure, the SRF is still only gradually being built and will only consist of target funding by $2023 .^{24}$ To date, the SRF has not been used. Plans for providing an additional "Common Backstop" to further strengthen the Banking Union have also only been agreed upon in principle.

This pinpoints a key vulnerability of the EU: namely, its lack of de facto risk sharing between Member States. ${ }^{25}$ Moralising narratives of "irresponsibility" are often raised to avoid EU-wide solidarity. Yet, these accusations are overly simplifying, as even Member States with well-funded healthcare systems were overwhelmed by the pandemic. ${ }^{26}$ Given the transboundary character of modern crises, national coping capacity is often insufficient, and nation states are increasingly forced to develop transboundary solutions. So far, institutional and attitudinal collaboration has been hesitant, nonbinding and fragmented, leaving the EU far from ready to adequately deal with systemic crises. Major crises might prompt bilateral assistance or the exchange of information and best practices, but usually not much more. ${ }^{27}$ To be sure, crises do sometimes form an impetus for further integration and the development of more and better transboundary crisis management capacities. ${ }^{28}$ The financial crisis did prompt the adoption of significant pieces of law, such as the establishment of the Single Supervisory Mechanism and the Single Resolution Board (SRB) - which, although far from perfect, are clear steps towards a more integrated Europe that is better prepared to withstand crises.

The lack of risk sharing is apparent in the COVID-19 crisis as well. In the wake of the 2003 SARS outbreak, the European Centre for Disease Prevention and Control (ECDC) was established to strengthen Europe's response capacity. Yet, its role in the current pandemic is limited, as it remains understaffed and under-budgeted. Moreover, despite the presence of the ECDC and legally binding instruments (such as the EU Decision on Serious Cross-border Threats to Health), the EU framework is limited by the competences of Member States, who have been encouraged to impose spending cuts on healthcare. To be sure, some progress is being made in terms of risk sharing and solidarity. A strategic (rescEU) ${ }^{29}$ stockpile of medical devices, such as ventilators and protective masks, has now been set up to address the emergency. However, this was preluded by Member States' attempts to implement export bans for critical medical equipment, ignoring any form of solidarity. ${ }^{30}$

\footnotetext{
$24<$ https://srb.europa.eu/en/content/single-resolution-fund $>$.

25 S Hutter (ed.), Politicising Europe: Integration and Mass Politics (Cambridge, Cambridge University Press 2016).

26 A Renda and R Castro, "Towards Stronger EU Governance of Health Threats after the COVID-19 Pandemic" (2020) 11 European Journal of Risk Regulation 273.

27 A Boin and M Ekengren, "Preparing for the World Risk Society: Towards a New Security Paradigm for the European Union" (2009) 17 Journal of Contingencies and Crisis Management 285.

28 A Boin and M Rhinard, "Managing Transboundary Crises: What Role for the European Union?" (2008) 10 International Studies Review 1. See also the contribution by A-L Beaussier and L Cabane in this issue for more on EU responses to crises and formalised coordination across sectors.

$29<$ https://ec.europa.eu/commission/presscorner/detail/en/ip_20_476>.

30 To be sure, examples of solidarity can be found, as some Member States sent specialised staff and air ambulances to severely affected areas and made their ICUs available to critical patients from bordering regions.
} 
As such, the final lesson is to complement a healthcare stress test with de facto risk sharing. The degree of integration and interdependence between Member States economically, politically and socially - means that, in dealing with crises, the EU is only as strong as its weakest link. If a stress test points out vulnerabilities, these need to be dealt with (at least in part) collectively. Our fate is connected to the fate of weaker countries in the system, and if we are not willing to share in their risk, this will eventually lead to a collapse of the system.

\section{Conclusion: pragmatic suggestions for a WAy fORWARd in EU HEALTHCARE REGULATION}

No country alone can face the transboundary and systemic crises of our globalised world. The COVID-19 crisis has shown how Member States' healthcare systems can be easily overwhelmed, causing damaging spill-over effects across borders. Similarly, the 2008 financial crisis showed that banks were interlinked and crises could not be contained within a single country. As a response to the financial crisis, a European Banking Union was established to ensure that EU banks are stronger and better supervised. A similar response - the creation of a European Health Union - seems appropriate in the wake of the COVID-19 crisis. Other tools used to strengthen the banking sector are the stress tests that assess the resilience of banks in times of crisis and pinpoint vulnerabilities. A stress test of healthcare systems could be similarly useful to evaluate their ability to handle pandemics and other shocks.

Several lessons can be passed on from one stress test to another. First, creating a level playing field can be useful, but standardisation is not always the best solution. This also implies that in a Health Union (minimum) common healthcare standards should be produced from the bottom up as the result of dialogue and deliberation, rather than imposed from the top down, where they risk existing solely on paper. Secondly, stress tests should be designed to avoid decoupling and gaming. Drawing on governmentality mechanisms, the exercise in itself might be used to encourage organisational change and better internal risk assessments in healthcare systems. Requiring healthcare systems to collect and keep track of (comparable) key data is not only useful within the scope of a stress test, but can remain useful for internal risk management as well. A Health Union needs EU-wide resolution mechanisms for vulnerable institutions that might "fail". Systemic problems warrant systemic solutions and de facto risk sharing between Member States. As future transboundary crises loom and nation states' uncoordinated approaches prove increasingly inadequate, we must continue moving towards a more solidary Europe. 